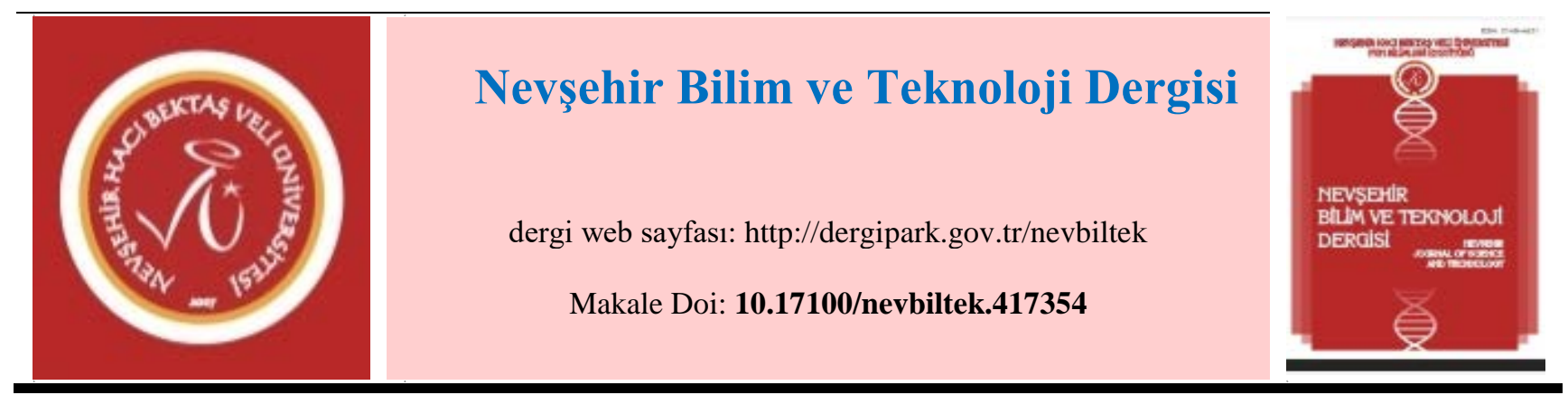

\title{
Biyomedikal Uygulamalar İçin Titanyum Esasılı Gözenekli TiNb Alaşımının Üretimi
}

\author{
Mehmet Kaya*1, Abdurrahman Yolun², Ömer Çakmak³, Fahrettin Yakuphanoğlu4, Ebru Elibol ${ }^{5}$, \\ Mustafa Köm ${ }^{6}$, Mehmet Güvenç ${ }^{7}$ \\ ${ }^{1}$ Bandırma Onyedi Eylül Üniversitesi, Denizcilik Fakültesi, Gemi İşaatı ve Gemi Makineleri Mühendisliği, \\ Bandırma/Balıkesir \\ ${ }^{2}$ İnönü üniversitesi, Fen Edebiyat Fakültesi, Fizik Bölümü, Malatya \\ ${ }^{3}$ Gebze Teknik Üniversitesi, Mühendislik Fakültesi, Malzeme Bilimi ve Mühendisliği, Kocaeli \\ ${ }^{4}$ Fırat Üniversitesi, Fen Fakültesi, Fizik Bölümü, Elazığ \\ ${ }^{5}$ Adlyaman Üniversitesi, Tıp Fakültesi, Histoloji Anabilim Dalı, Adıyaman \\ ${ }^{6}$ Fırat Üniversitesi, Veteriner Fakültesi, Cerrahi Anabilim Dalı, Elazı̆̆ \\ ${ }^{7}$ Adıyaman Üniversitesi, Fen Edebiyat Fakültesi, Biyoloji Bölümü, Adıyaman
}

Öz

Titanyum esaslı alaşımların biyomalzeme olarak kullanımını yaygınlaştırmak için son yıllarda gözenekli implant malzemesi olarak üretimi ve uygulanması üzerine yoğun çalışmalar yapılmaktadır. Ti-esaslı alaşımlar yüksek korozyon direnci, düşük elastik modülü ve üstün biyouyumluluğu nedeniyle medikal uygulamalarda yaygın olarak kullanılmaktadır. Bu tür alaşımlar özellikle sert doku implantları olarak tercih edilmektedirler. Alaşım gözenekli malzeme olarak üretildiği zaman vücut içerisinde canlı dokunun ilerlemesine, kan ve besin taşınmasına imkan sağlayacağı ve kemik ile iyi bir bağ oluşturacağı gerçektir. Bu nedenle bu çalışmada, yüksek saflıkta element tozları kullanılarak saf titanyum ve titanyum esaslı Ti-10Nb alaşımı üretildi. Üretim sonrası, saf titanyum yapısının tamamen $\alpha$ fazından ibaret olduğu, Ti-10Nb alaşımının yapısında ise $\alpha$ fazına ilaveten $\beta$ ve $\alpha "$ fazlarının varlığı tespit edildi. Ti-10Nb alaşımının gözenek oranının saf titanyum numunesine göre daha fazla ve elastik modülünün ise kemik yapısına yakın olduğu belirlendi. Üretilen Ti-10Nb numunesi mikroyapı ve basma dayanımı açısından ideal bir implant malzemesi olarak daha uygun olacağı anlaşııldı.

Anahtar Kelimeler: TiNb, Toz metalurjisi, Biyomalzeme

** e-mail: mehmetkaya75@hotmail.com 


\title{
Production of Titanium Based Porous TiNb Alloy for Biomedical Applications
}

\begin{abstract}
In recent years, intensive studies have been carried out on the production and application of titanium-based alloys as porous implant materials in order to promote the use of titanium-based alloys as biomolecules. Ti-based alloys are widely used in medical applications due to their high corrosion resistance, low elastic modulus and superior biocompatibility. Such alloys are especially preferred as hard tissue implants. When the alloy is produced as a porous material it is essential that it will allow the passage of live tissue through the body, allowing blood and nutrient transport, and a good bond with the bone. For this reason, pure titanium and titanium-based Ti-10Nb alloy was produced in this work using high purity elemental powders. After the production, the pure titanium structure consisted entirely of $\alpha$ phase, while in the structure of the Ti- $10 \mathrm{Nb}$ alloy, $\beta$ and $\alpha$ " phases were detected in addition to $\alpha$ phase. It was determined that the porosity ratio of Ti-10Nb alloy is higher than that of pure titanium specimen and the elastic modulus is closer to bone structure. It was understood that Ti-10Nb specimen produced would be more suitable as an ideal implant material in terms of microstructure and compressive strength.
\end{abstract}

Keywords: TiNb, Powder metallurgy, Biomaterial

\section{Giriş}

Titanyum ve titanyum esaslı alaşımlar metalik biyomalzeme olarak modern bilimin birçok alanında son 50 yıldır yaygın bir şekilde kullanılmaktadır [1-3]. Özellikle saf titanyum yanında Ti-6Al-4V ve TiNi gibi alaşımlar medikal uygulamalarda ve implant malzeme olarak kullanılmaktadır. Bu alaşımların vücut içerisinde üstün biyouyumluluk, iyi korozyon direnci ve yüksek basma dayanımı gibi özellikler sergilediği bilinmektedir [4-8]. Fakat, bu alaşımların elastik modüllerinin ve gerilme dayanımlarının insan kemiği ile kıyaslandığında yüksek oldukları aşikar olup kemik dokunun aşınmasına neden olduğu öngörülmektedir [9,10]. Ayrıca, son yıllarda Ni, V ve Al gibi bazı elementlerinin alaşım içerisinde iyon salınımı oluşturarak hücre ölümlerine ve uzun süreli sağlık problemlerine neden oldukları belirtilmektedir [8]. Titanyum iyi bir biyouyumluluk özelliği göstermesine rağmen yüksek saflıkta element kullanımı korozyon açısından pek uygun görülmemektedir. Bu sebepten dolayı Ti içerisine biyouyumluluk açısından sorun teşkil etmeyen elementlerin ilave edilmesi ihtiyaç duyulmaktadır.

Son yıllarda, biyouyumluluk açısından sorun teşkil etmeyen $\mathrm{Nb}, \mathrm{Zr}$, Sn, Ta gibi elementler Ti içerisine ilave edilerek $\beta$ fazlı titanyum esaslı alaşımların üretimi üzerine yoğun çalışmalar bulunmaktadır. Saf titanyum oda sıcaklığında $\alpha$ fazına sahip olup kemik yapıya göre oldukça sert ve böyle bir implant malzeme kemiğin aşınmasına neden olmaktadır. Diğer taraftan $\beta$ fazlı titanyum alaşımı daha esnek olup kemikle benzer mekanik özellik sergilemektedir. Ti içerisine ilave edilen $\mathrm{Nb}$, Sn, Ta ve Zr gibi elementler $\beta$ fazlı alaşım oluşumunu desteklemektedirler $[4,11,12]$. Son zamanlarda özellikle titanyum içerisine farklı oranlarda niyobyum ilave edilerek titanyum esaslı alaşım üretimi üzerine birçok çalışma yapılmaktadır. Ayrıca bu alaşımın gözenekli malzeme olarak üretimi ve canlı ortamda uygulanması üzerine de çalışmalar devam etmektedir [13-15]. Bunun sebebi niyobyum ilavesi ile düşük elastik modüllü $\beta$ fazına sahip alaşım elde edilmesi ve böylece kemiğin aşınmasının önlenmesidir. Ayrıca gözenekli yapı sayesinde implant ile kemik doku arasında daha sağlam bağ oluşumu, vücut içerisinde besin taşınması, kan ve kemik doku gibi maddelerin ilerlemesinin mümkün olmasıdır [16-19]. Bu nedenle bu çalışmada, yüksek saflıkta titanyum ve niyobyum 
element tozları kullanılarak geleneksel sinterleme ile gözenekli ve Ti esaslı Ti-10Nb alaşımı implant malzemesi olarak üretilmeye çalışıldı.

\section{Deneysel işlemler}

$\mathrm{Bu}$ çalışmada kullanılan tozların özellikleri Tablo 1'de verilmiştir. Yüksek saflıktaki Ti ve Nb tozları Ti-10Nb atomik oranlarında karıştırıldı. Ti-10Nb atomik oranı ikili Ti-Nb denge diyagramına göre çoğunlukla $\beta$ fazlı yapısının elde edilmesi amacıyla tercih edildi. Karışımın homojen olması için köşeli bir kap içerisinde 1/4 doluluk oranında torna tezgâhında 45 derecelik eğimli olacak şekilde bağlanarak 24 devir/dakika hızında 12 saat süreyle karıştırıldı. Karıştırılan tozlar özel olarak imal edilen bir kalıp içerisinde 10x15 mm boyutlarında silindir şeklinde $300 \mathrm{MPa}$ basınçla briketlendi ve sonrasında argon gazı korumalı bir firın içerisinde $1400{ }^{\circ} \mathrm{C}$ 'de 2 saat süreyle sinterlendi. Ayrıca kıyaslamak amacıyla saf Ti tozları da aynı basınçla briketlenerek benzer şekilde sinterlendi. Sinterleme sıcaklığına ortam sıcaklığını çıkarmak için fırın sıcaklığ $5^{\circ} \mathrm{C} /$ dakika 1 sıtma hızı ile çıkartıldı ve 2 saatlik sinterleme süresinden sonra benzer olarak oda sıcaklığına soğutuldu [20, 21].

Üretilen numunelerin genel gözenek oranları $(\varepsilon)$ teorik ve gerçek yoğunlukları dikkate alınarak $\varepsilon=\left(1-d / d_{0}\right)$ denklemi ile hesaplandı. Denklemde $d$ gözenekli numunenin yoğunluğu, $d_{0}$ ise kompozisyona bağlı olarak onun teorik yoğunluğudur. Hesaplanan gözenek oranları açık ve kapalı gözeneklerin genelini temsil etmektedir. Bu çalışmada açık gözenek fazla olmadığı için hesaplanmadı [20,21].

Tablo 1. Kullanılan tozların özellikleri.

\begin{tabular}{ccccc}
\hline Tozlar & Marka & Saflık (\%) & Toz boyutu ( $\mu m)$ & $\begin{array}{c}\text { Karışım oranı (\% } \\
\text { atomik) }\end{array}$ \\
\hline Titanyum (Ti) & Alfa Aesar & 99.5 & -44 & 90 \\
\hline Niyobyum (Nb) & Alfa Aesar & 99.8 & -5 & 10 \\
\hline
\end{tabular}

Sinterlenen numunelerin mikroyapılarının incelenmesi için numunelerin yüzeyleri 300-1200 mesh’lik SiC su zımparası ile zımparalandı. Zımparalanmış yüzeyler 1 ve $3 \mu \mathrm{m}$ 'lik elmas solüsyon ve çuha kullanılarak parlatıldı. Parlatılan numuneler $3 \mathrm{~mL} \mathrm{HF}$ : 6 mL $\mathrm{HNO}_{3}: 100 \mathrm{~mL} \mathrm{H} \mathrm{H}_{2} \mathrm{O}$ oranlarında Kroll çözeltisi kullanılarak dağlandı. Parlatılan ve dağlanan numunelerin yüzey özelliklerini incelemek için Leica DM 750M marka optik mikroskobu cihazı ve EDX donanımlı Zeiss EVO LS 10 marka SEM cihazı kullanıldı. Üretilen numunelerin fazlarını tespit edebilmek amacıyla X1şını difraktometresi ölçümleri yapıldı. X-1şını difraktogramı için, bilgisayar kontrollü bir Rigaku RadB DMAX-II X1şını difraktometresi kullanıldı. Difraktometrede süzülmüş $1,54056 \AA$ dalga boylu $\mathrm{Cu}-\mathrm{K}_{\alpha}$ 1şını kullanıldı. Alınan difraktogram esnasında difraktometrenin $2 \theta$ açısı tarama hızı $6 \%$ dakika olarak seçildi. Numunelerin basma dayanımlarının belirlenmesi için 0,2 mm/dakika ilerleme hızı ile kırılıncaya kadar kuvvet uygulandı. Böylece maksimum dayanımları, birim şekil değiştirme oranları ve elastik modülleri belirlendi.

\section{Bulgular ve Tartışma}


Üretilen numunelerde gözenek oranları sırasıyla saf Ti ve Ti-10Nb alaşımı için 3,2 ve $5.4 \mathrm{gr} / \mathrm{cm}^{3}$ olarak belirlendi. $\mathrm{Nb}$ ilavesi ile gözenek oranı artmaktadır. Bu durum farklı tozların karıştııılmasında çok sıkı kompakt oluşturmanın zorluğunu belirtmektedir. Gözenekler genel olarak kapalı şekildedir. Gözenek yapıcı ekstra malzeme kullanılmadığından gözenek oranları düşük olmaktadır. Şekil 1’teki SEM görüntülerinde saf Ti için yapının tamamen $\alpha$ fazına ait olduğu alınan EDX (Şekil 1a, atomik \%100Ti) ile anlaşılmaktadır. Ti-10Nb için (Şekil 1b) açık renkli yapıda obje-1 bölgesinde $\mathrm{Nb}$ oranın alınan EDX sonucuna göre atomik Ti-12.7Nb olduğu ve bu yapının $\beta$ faz yapısına ait olduğu anlaşılmaktadır. Aynı görüntü üzerinde Obje-2 içerisinde koyu renkli bölgeye göre EDX sonucu Ti-8.4Nb olup bu yapının da $\alpha$ fazına sahip olduğu anlaşılmaktadır. Ti-Nb alaşımlarında $\mathrm{Nb}$ içeriğinin artması ile $\beta$ fazı yapısının oluşumu ikili Ti-Nb denge diyagramına göre beklenen bir durumdur [22]. SEM görüntülerinde koyu renkli bölgelerin $\alpha$ ve açık renkli bölgelerin ise $\beta$ fazlarına ait olduğu literatür çalışmasına ve denge diyagramına (Şekil 2) göre belirlendi [23]. Ayrıca $\alpha$ ve $\beta$ fazları XRD çalışması ile de belirlendi. SEM görüntülerinde bazı bölgelerde açık ve koyu renkli bölgelerin tabakalı şekilde olduğu görülmektedir. Böyle $\alpha$ ve $\beta$ fazlarının tabakalı şekilde olması $(\alpha+\beta)$ Widmanstätten yapı olarak adlandırılmaktadır [8]. Ti-Nb alaşımında $\beta$-Ti fazının $\alpha^{\prime \prime}$ martensit fazla kıyaslandığında daha baskın olduğu Ma ve ark. tarafindan doğrulandı [24].
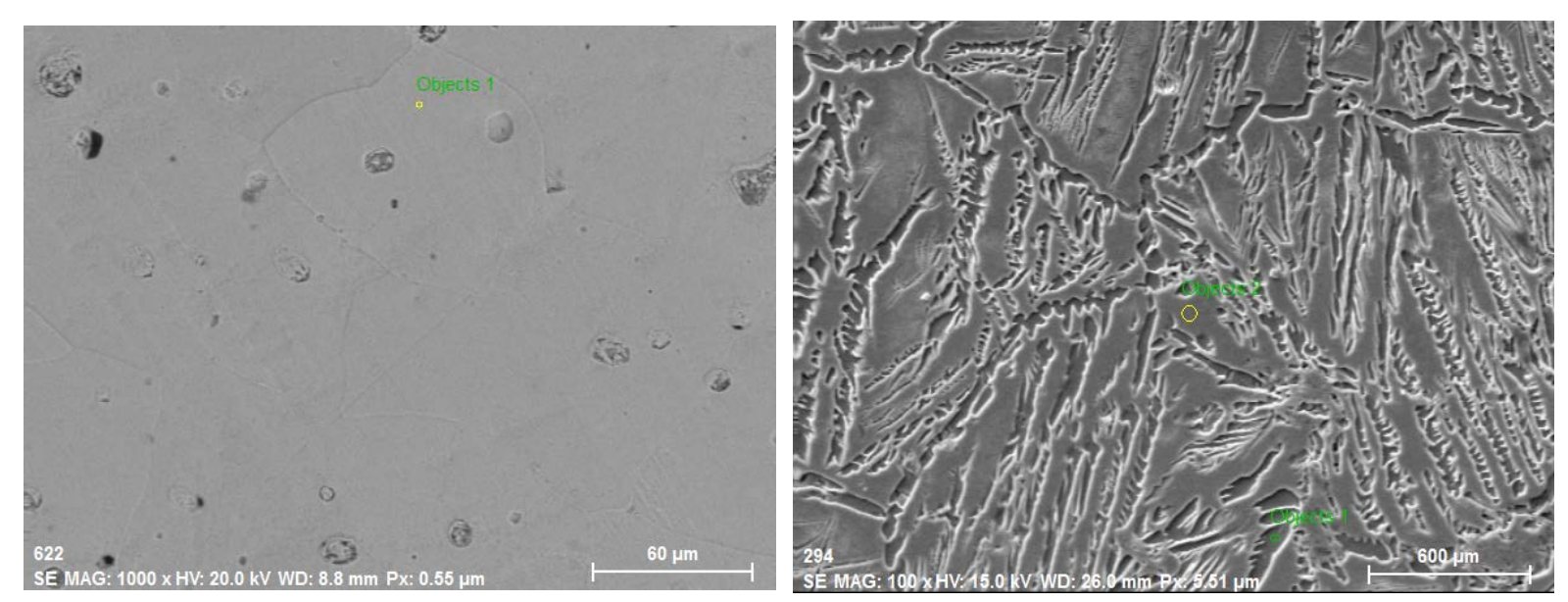

Şekil 1. $300 \mathrm{MPa}$ basınçla briketlendikten sonra $1400^{\circ} \mathrm{C}$ sıcaklıkta 2 saat süreyle sinterlenen numunelerinin SEM görüntüleri, (a) saf Ti, (b) Ti-10Nb alaşım.

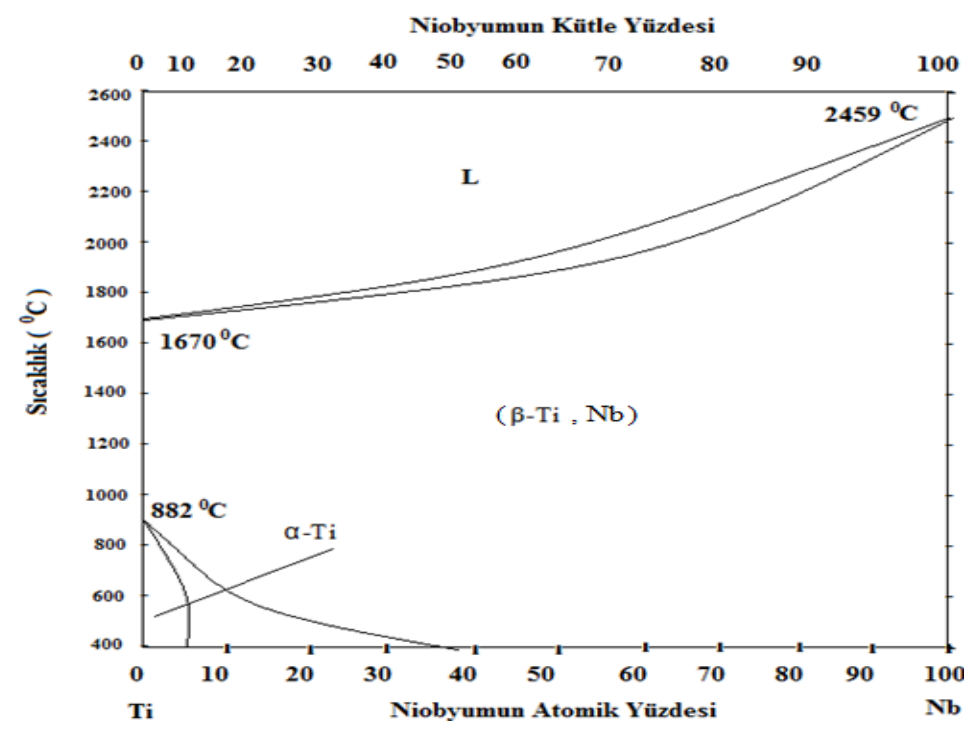

Şekil 2. Titanyumun (Ti) ile Niobyum (Nb) faz diyagramı. 
Ti-Nb ikili alaşımının faz denge diyagramı Şekil 2'de gösterilmiştir. Faz dengesine göre saf titanyum için $\alpha$ dan $\beta$ ya dönüşüm $882^{\circ} \mathrm{C}$ de olmaktadır. Nb güçlü $\beta$ dengeleyicisi olarak davrandığı için, $\mathrm{Nb}$ ilavesi $\alpha$ 'dan $\beta$ 'ya dönüşüm faz sıcaklığını önemli ölçüde azaltmaktadır. Faz dönüşüm diyagramına göre, Ti-Nb alaşımında Nb oranı kütlece \%40 oranından fazla olduğunda $\beta$ fazının çok düşük sıcaklıklarda bile koruduğu görülmektedir [11].

Ti alaşımları özellikle $\alpha+\beta$ fazındakiler, oldukça yüksek oranda biyouyumluluk göstermeleri ve düşük oranda alerjik özellikler göstermeleri nedeniyle yaygın olarak insan vücudunda kullanılmaktadır. Ti alaşımları $\alpha, \beta$ ve $\alpha+\beta$ (Widmanstätten) şeklinde olmak üzere 3 grup olarak sınıflandırılmaktadır [8]. Üretilen numunelerin faz bileşenleri XRD desenleri ile tespit edilerek Şekil 3'de gösterilmiştir. Saf Ti için yapının tamamen hegzagonal yapıda ( $\alpha$ fazı) olduğu anlaşılmaktadır (Şekil3a). Ti-10Nb alaşımı için hacim merkezli kübik yapı (bcc) $\beta$ fazı, ortorombok $\alpha^{\prime \prime}$ martensit fazı ve hegzagonal sıkı paket yapı (hcp) $\alpha$ fazlarının varlığı belirlenmiştir (Şekil 3b). Bu yapıların $(\beta$ ve $\alpha+\beta)$ biyouyumlu gözenekli malzemeler için en çok tercih edilen faz yapıları oldukları literatürde sıklıkla belirtilmektedir [25- 27]. Bunun yanısıra, sinterlenme ile üretilen TiNb numunelerinde Widmanstätten benzeri yapının soğuk presleme basıncının artması ve gözenek oranının azalması ile arttığı belirtilmektedir [3]. Bu yapılar içerisinde $\alpha$ fazı çökelmeleri çoğunlukla $\beta$ tane sınırları boyunca görülmektedir. TiNb alaşımında bazı fazların $\alpha^{\prime \prime}$ martensit yapı şeklinde görüldüğü kaydedilmiştir [5, 25-27]. Titanyum alaşımlarında $\beta$ dengeleyicisi faz dengelerini değiştirir. Denge koşulları altında $\beta$ fazının artması durumunda mikroyapı içerisinde $\alpha$ fazının hacimsel oranda azaldığı sonucu ortaya çıkmaktadır [28]. Literatürdeki çok sayıdaki çalışmalarda $\beta$ tipi Ti esaslı şekil hatırlamalı alaşımlarda $\beta$ fazından $\alpha^{\prime \prime}$ fazına geçişte gerçekleşen martensit dönüşümün su ile hızlı soğutmadan kaynaklandığı belirtilmektedir [28-30].

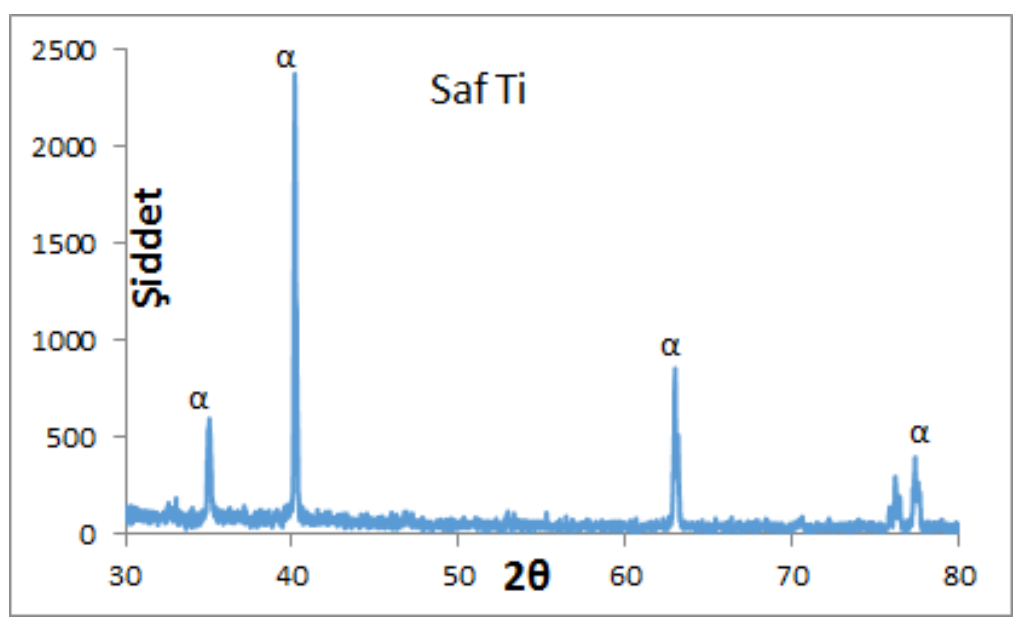

(a) 


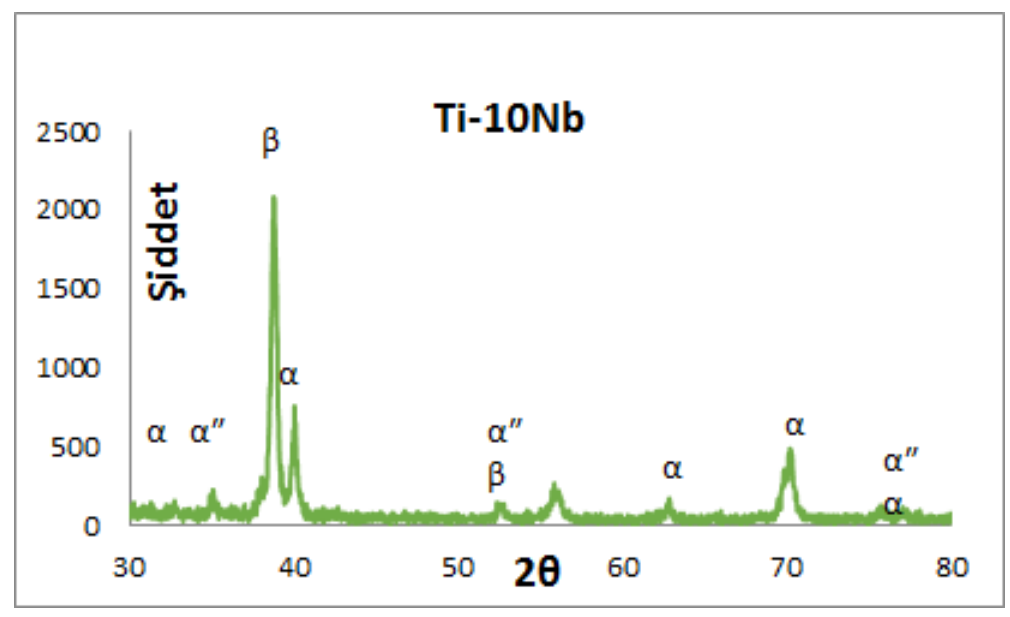

(b)

Şekil 3. $1400{ }^{\circ} \mathrm{C}$ ile üretilen (a) saf Ti ve (b) Ti-10Nb numuneleri için XRD görüntüleri.

Üretilen numunelerin basma dayanımları Şekil 4'de gösterilmektedir. Saf Ti için basma dayanımı yaklaşık 1350 MPa, elastik modülü ise $80 \mathrm{GPa}$ civarındadır. Ti-10Nb için basma dayanımı yaklaşı $900 \mathrm{MPa}$ ve elastik modülü ise 30 GPa civarındadır. Saf Ti için gözenek oranının az olması basma dayanımını da etkilemektedir. Yani, gözenek oranının azalması ile basma dayanımı artmaktadır. Numunelerin basma dayanımları kemiğin basma dayanımından (170-200 $\mathrm{MPa}$ ) oldukça fazladır. Benzer şekilde elastik modülleri de kemiğin elastik (sert doku kemiklerin yaklaşık $20 \mathrm{GPa}$ ) modülünden fazladır. Ancak gözenek oranları kemiğin gözenek yapısına (30-90 gözenek oranı) göre düşüktür [21].

Yapılan literatür çalışmaları gösterdi ki, Ti-Nb alaşımlarının tavşan vücudu içerisinde implant malzemesi olarak kullanılması durumunda herhangi bir hücre zehirlenmesi durumuna neden olmadığı ve doku ile biyo uyumlu olduğu görülmüştür [31]. Toksit etkinin yanı sıra bir diğer sorun implant malzeme ile kemik doku arasındaki sertlik sorunudur. İmplant malzemenin fazla sert olması durumunda kemiğin implant ile olan teması süresince iyileşme süresi uzamakta ve sert implant malzeme zamanla kemiğin aşınmasına neden olmaktadır [32-34]. Biyo malzeme kullanımında kırık, çatlak ve malzemenin deformasyona uğraması gibi istenmeyen durumlar, üretilen malzemenin mikro yapısına, mekanik özelliklerine, korozyon direncine ve üretim yöntemine dayandırılmaktadır. Ti-Nb alaşımlarının biyo uyumlu oldukları ve mükemmel derecede özellikler gösterdikleri doğrulanmıştır [35]. Yapılan literatür incelemeleri ile anlaşılmaktadır ki malzeme bileşenlerinin değişimi ile gözenek oranı ve biyo uyumlu olması arasında bir ilişki mevcuttur. Dolayısı ile Ti$\mathrm{Nb}$ alaşımında gözenekli yapı olması kemik dokusunun oluşumu açısından oldukça tercih edilen bir netice vermektedir [36]. İmplant malzemede zayıf yüzeysel özellikler önemli ölçüde sürtünmeye ve akabinde malzemede aşınmaya neden olmaktadır. Bu durum da implant malzemenin ömrünü azaltacak ve akabinde hem maddi hem de manevi açıdan olumsuz durumlara neden olacaktır. Bu durumlara en iyi çözüm $\beta$ tipi Ti alaşımlarını farklı kompozisyonlarda üreterek en iyi malzemeyi bulmak esas hedef olmaktadır. Ti-Nb alaşımları bu durumlara kısmen de olsa bir rahatlama getirse de bu konu hala çalışılmaya ve geliştirilmeye devam edilmektedir [8]. 


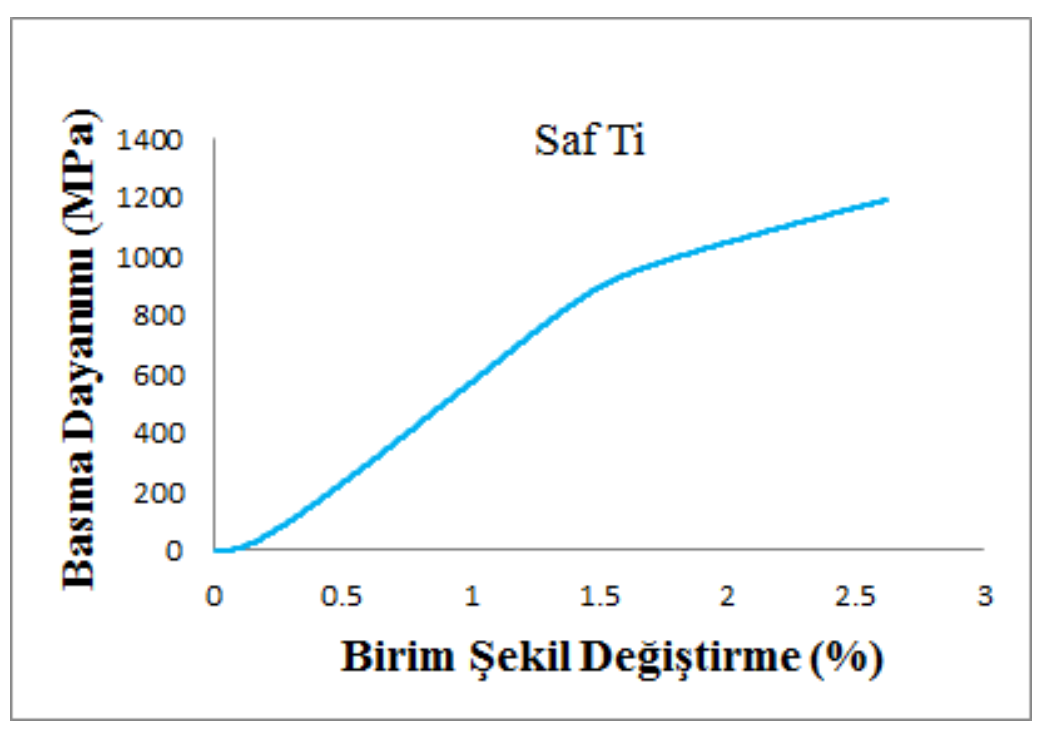

(a)

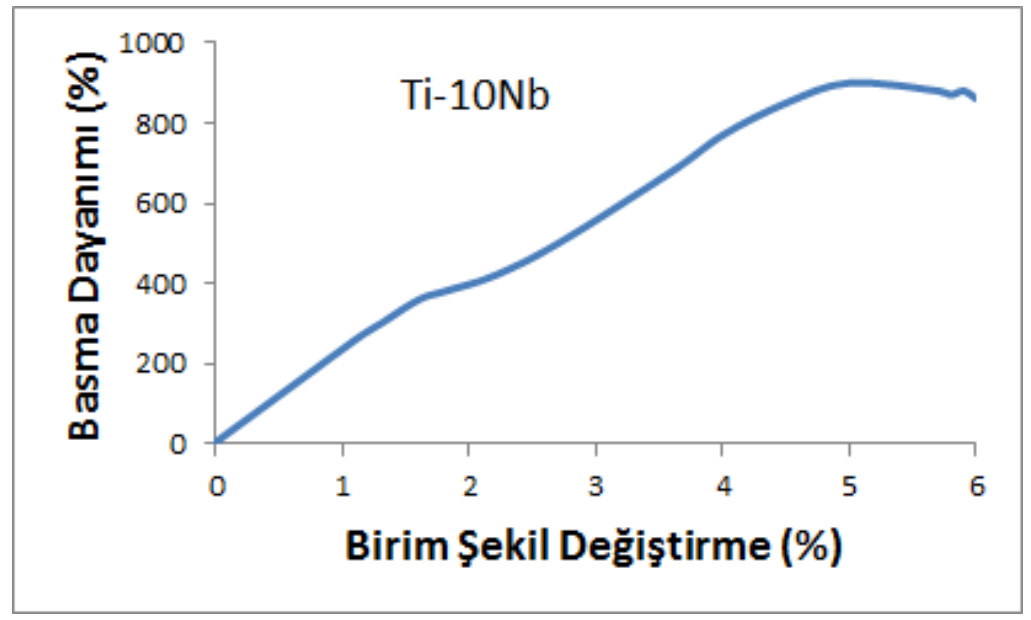

(b)

Figure 4. Üretilen numunelerin basma dayanımları ve birim şekil değişimi, (a) saf Ti, (b) Ti-10Nb

\section{Sonuçlar}

$\mathrm{Bu}$ çalışmada yüksek saflıkta element tozları kullanılarak saf Ti ve Ti-10Nb toz numuneleri $1400{ }^{\circ} \mathrm{C}$ 'de 2 saat süreyle geleneksel sinterleme yöntemiyle başarılı bir şekilde üretildi. Numunelerin gözenek oranları ideal bir implant için düşüktür. $\mathrm{Bu}$ nedenle numuneler üretilirken amonyum bikarbonat gibi gözenek oluşturucu ekstra malzemelerin kullanılması ileriki çalışmalara fayda sağlayacaktır. Bu tür alaşımlar literatürden henüz yeni çalışılmaya başlanmış olup yoğun bir şekilde devam etmektedir. SEM ve XRD analizleri sonucu saf Ti için yapının tek faz, Ti-10Nb için ise $\alpha$ ve $\beta$ fazlarının yanı sıra $(\alpha+\beta)$ Widmanstätten benzeri yapıların varlı̆̆ı belirlendi. Ayrıca XRD desenleri ile az miktarda $\alpha^{\prime \prime}$ martensit yapının varlığı tespit edildi. Üretilen numunelerin basma dayanımlarının sert kemik dokuya göre oldukça fazla olduğu elastik modüllerinin ise yakın olduğu belirlendi. Numunelerin elastik modüllerinin düşmesine $\mathrm{Nb}$ ilavesi ile oluşan $\beta$ faz yapısı katkı sağlamaktadır. Üretilen Ti-10Nb numunesi mikroyapı ve mekanik özellikler açısından saf Ti numunesine göre daha ideal bir implant malzemesidir. 


\section{Teşekkür}

Bu çalışma Adıyaman Üniversitesi BAP birimi tarafından MÜFMAP 2015/0017 nolu proje ile başlıca desteklenmiştir.

\section{Kaynaklar}

[1] Wang X., Chen Y., Xu L., Liu Z., Woo K.D., Effects of Sn content on the microstructure, mechanical properties and biocompatibility of Ti-Nb-Sn/hydroxyapatite biocomposites synthesized by powder metallurgy, Materials and Design, 49, 511-519, 2013

[2] Biesiekierski A., Li J., Li Y., Ping D., Yamabe-Mitarai Y., Wend C., Investigations into Ti-(Nb,Ta)-Fe alloys for biomedical applications, Acta Biomaterialia, 32, 336-347, 2016

[3] Henriques V.A.R., Bellinati C.E., Da Silva C.R.M., Production of Ti-6\%Al-7\%Nb alloy by powder metallurgy (P/M), Journal of Materials Processing Technology, 118, 212-215, 2001

[4] Bottino M.C., Coelho P.G., Henriques V.A.R., Higa O.Z., Bressiani A.H.A., Bressiani J.C., Processing, characterization, and in vitro/in vivo evaluations of powder metallurgy processed Ti-13Nb-13Zr alloys, Journal of Biomedical Materials Research, 88-3, 689-696, 2009

[5] Zhao, Chang K., Ebel T., Nie H., Willumeit R., Pyczak F., Sintering behavior and mechanical properties D. of a metal injection molded Ti-Nb binary alloy as biomaterial, Journal of Alloys and Compounds, 640, 393-400, 2015

[6] De Oliveira C.S.S., Griza S., De Oliveira M. V., Ribeiro A.A., Leite M.B., Study of the porous Ti35Nb alloy processing parameters for implant applications, Powder Technology, 281, 91-98, 2015

[7] Han M.K., Kim J.Y., Hwang M.J., Song H.J. and Park Y.J., Effect of Nb on the Microstructure, Mechanical Properties, Corrosion Behavior, and Cytotoxicity of Ti-Nb Alloys, Materials, 8(9), 5986-6003, 2015

[8] Khorasani A.M., Goldberg M., Doeven E.H., and Littlefair G., Titanium in Biomedical Applications-Properties and Fabrication: A Review, Journal of Biomaterials and Tissue Engineering, 5, 593-619, 2015

[9] Dos Santosa D.R., Henriques V.AR., Cairo C.A.A., Dos Santos Pereira M., Production of a Low Young Modulus Titanium Alloy by Powder Metallurgy, Materials Research, 8(4), 439-442, 2005

[10] Lai M., Gao Y., Yuan B., Zhu M., Remarkable superelasticity of sintered Ti-Nb alloys by Ms adjustment via oxygen regulation, Materials and Design, 87, 466-472, 2015

[11] Sharma B., Vajpai S.K., Ameyama K., Microstructure and properties of beta Ti-Nb alloy prepared by powder metallurgy route using titanium hydride powder, Journal of Alloys and Compounds, 656, 978-986, 2016

[12] Zhaoa D., Changb K., Ebela T., Qianc M., Willumeita R., Yanc M., Pyczaka F., Microstructure and mechanical behavior of metal injection molded Ti-Nb binary alloys as biomedical material, Journal of the Mechanical Behavior of Biomedical Materials, 28, 171-182, 2013

[13] Bidaux J.E., Pasquier R., Arbaizar M. R., Girard H. and Morelli E. C., Low elastic modulus Ti-17Nb processed by powder injection moulding and post-sintering heat treatments, Powder Metallurgy, 57(5), 320-323, 2014 
[14] Mantani Y., Tajima M., Phase transformation of quenched a11 martensite by aging in Ti-Nb alloys, Materials Science and Engineering A, 438-440, 315-319, 2006

[15] Cui Y., Li Y., Luo K., Xu H., Microstructure and shape memory effect of Ti-20Zr-10Nb alloy, Materials Science and Engineering A, 527, 652-656, 2010

[16] Taddeia E.B., Henriques V.A.R., Silva C.R.M.,. Cairo C.A.A, Production of new titanium alloy for orthopedic implants, Materials Science and Engineering C, 24, 683-687, 2004

[17] Oliveira C.S.S., Griza S., Oliveira M.V., Ribeiro A.A., Leite M.B., Study of the porous Ti35Nb alloy processing parameters for implant applications, Powder Technology, 281, 91-98, 2015

[18] Bönisch M., Calin M., Waitz T., Panigrahi A., Zehetbauer M., Gebert A., Skrotzki W. and Eckert J., Thermal stability and phase transformations of martensitic Ti-Nb alloys, Sci. Technol. Adv. Mater., 14, 1-9, 2013

[19] Ruan J., Yang H., Weng X., Miao J., Zhou K., Preparation and characterization of biomedical highly porous Ti-Nb alloy, J. Mater Sci: Mater Med, 27:76, 2016

[20] Yolun A., Toz metalurjisi ile üretilen TiNb alaşımının biyouyumluluk özelliğinin incelenmesi, Adıyaman Üniversitesi, Fen Bilimleri Enstitüsü, Yüksek lisans tezi, 95s, Adiyaman, 2016

[21] Çakmak Ö., TiNbSn alaşımının toz metalurjisi ile üretimi ve biyouyumluluk özelliğinin incelenmesi, Adıyaman Üniversitesi, Fen Bilimleri Enstitüsü, Yüksek lisans tezi, 115s, Adıyaman, 2017

[22] Hao Y.L., Li S.J., Sun S.Y., Yang R.., Effect of Zr and Sn on Young's modulus and superelasticity of Ti-Nbbased alloys, Materials Science and Engineering A, 441, 112-118, 2006

[23] De Almeida L.H., Bastos I.N., Santos I.D., Dutra A.J.B., Nunes C.A., Gabriel S.B., Corrosion resistance of aged Ti-Mo-Nb alloys for biomedical applications, Journal of Alloys and Compounds, 615, 666-669, 2014

[24] Ma L.W., Chung C.Y., Tong Y.X., and Zheng Y.F., Properties of Porous TiNbZr Shape Memory Alloy Fabricated by Mechanical Alloying and Hot Isostatic Pressing, Journal of Materials Engineering and Performance, 20, 783-786, 2011

[25] Kim H.Y., Satoru H., Kim J., Hosoda H., and Miyazaki S., Mechanical properties and shape memory behavior of Ti-Nb alloys, Materials Transactions, 45(7), 2443-2448, 2004

[26] Chelariua R., Bolatb G., Izquierdoc J., Marecib D., Gordind D.M., Gloriantd T., Soutoc R.M., Metastable beta Ti-Nb-Mo alloys with improved corrosion resistance in saline solution, Electrochimica Acta, 137, 280-289, 2014

[27] Fojt J., Joska L., Malek J., Sefl V., Corrosion behavior of Ti-39Nb alloy for dentistry, Materials Science and Engineering C, 56, 532-537, 2015

[28] Cremasco A., Andrade P.N., Contieri R.J., Lopes E.S.N., Afonso C.R.M., Caram R., Correlations between aging heat treatment, $\omega$ phase precipitation and mechanical properties of a cast Ti-Nb alloy, Materials and Design, 32, 2387-2390, 2011 
[29] Bai Y.J., Wang Y.B., Cheng Y., Deng F., Zheng Y.F., Wei S.C., Comparative study on the corrosion behavior of Ti-Nb and TMA alloys for dental application in various artificial solutions, Materials Science and Engineering C, 31, 702-711, 2011

[30] Cremasco A., Osorio W.R., Freire C.M.A., Garcia A., Caram R., Electrochemical corrosion behavior of a Ti35Nb alloy for medical prostheses, Electrochimica Acta, 53, 4867-4874, 2008

[31] Wang Y. B., Zheng Y.F., Corrosion behaviour and biocompatibility evaluation of low modulus Ti-16Nb shape memory alloy as potential biomaterial, Materials Letters, 63, 1293-1295, 2009

[32] Zhuravleva K., Müller R., Schultz L., Eckert J., Gebert A., Bobeth M., Cuniberti G., Determination of the Young's modulus of porous ß-type Ti-40Nb by finite element analysis, Materials and Design, 64, 1-8, 2014

[33] Wang B.L., Wang Y.B., Zheng Y.F., Phase constitution, mechanical property and corrosion resistance of the Ti-Nb alloys, Key Engineering materials, 324-325, 655-658, 2006

[34] Xiao-jun W., Effects of alkali and heat treatment on strength of porous Ti35Nb, Trans. Nonferrous Met. Soc. China, 21, 1335-1339, 2011

[35] Kanetaka H., Shimizu Y., Hosoda H., Tomizuka R., Suzuki A., Urayama S., Inamura T., Miyazaki S. and Yamamoto T.T., Orthodontic Tooth Movement in Rats Using Ni-Free Ti-Based Shape Memory Alloy Wire, Materials Transactions, 48( 3), 367-372, 2007

[36] De Andrade D.P., De Vasconcellos L.M.R., Carvalho I.C.S., De Brito Penna Forte L.F., De Souza Santos E.L., Do Prado R.F., Dos Santos D.R., Cairo C.A.A., Carvalho Y.R., Titanium-35Niobium alloy as a potential material for biomedical implants: In vitro study, Materials Science and Engineering C, 56, 538-544, 2015 


\section{Extended Abstract}

In recent years, intensive studies have been carried out on the production and application of titanium-based alloys as porous implant materials in order to promote the use of titanium-based alloys as biomolecules. Ti-based alloys are widely used in medical applications due to their high corrosion resistance, low elastic modulus and superior biocompatibility. Such alloys are especially preferred as hard tissue implants. When the alloy is produced as a porous material it is essential that it will allow the passage of live tissue through the body, allowing blood and nutrient transport, and a good bond with the bone. For this reason, pure titanium and titanium-based Ti-10Nb alloy was produced in this work using high purity elemental powders. After the production, the pure titanium structure consisted entirely of $\alpha$ phase, while in the structure of the Ti-10Nb alloy, $\beta$ and $\alpha$ " phases were detected in addition to $\alpha$ phase. It was determined that the porosity ratio of Ti-10Nb alloy is higher than that of pure titanium specimen and the elastic modulus is closer to bone structure. It was understood that Ti-10Nb specimen produced would be more suitable as an ideal implant material in terms of microstructure and compressive strength.

\section{Introduction}

Titanium and titanium-based alloys have been used extensively in the last 50 years in many areas of modern science as metallic biomaterials [1-3]. In particular, alloys such as Ti-6Al-4V and TiNi, besides pure titanium, are used in medical applications and as implant materials. These alloys are known to exhibit superior biocompatibility, good corrosion resistance and high compressive strength within the body [4-8]. However, it is predicted that elastic modulus and tensile strength of these alloys are high when compared with human bone, and cause bone contact wear [9,10]. In addition, some elements such as $\mathrm{Ni}, \mathrm{V}$ and $\mathrm{Al}$ have been reported to cause ion mobility in the alloy in recent years, leading to cell death and prolonged health problems [8]. Though titanium shows good biocompatibility, the use of highpurity elements is not well suited for corrosion. For this reason, it is necessary to add elements, which do not cause problems in terms of biocompatibility to Ti.

In recent years, there have been intensive studies on the production of $\beta$-phase titanium-based alloys by adding elements such as $\mathrm{Nb}, \mathrm{Zr}$, Sn and Ta, which are not problematic in terms of biocompatibility, into Ti. Pure titanium has $\alpha$ phase at room temperature and is very hard compared to bone structure, and such implant causes material bones wear. On the other hand, the $\beta$-phase titanium alloy is more flexible and exhibits similar mechanical properties to bones. Elements such as $\mathrm{Nb}$, Sn, Ta and $\mathrm{Zr}$ added to Ti support the formation of $\beta$-phase alloys [4,11,12]. Recently, many studies have been carried out on the production of titanium-based alloys, especially by adding niobium in different proportions to titanium. In addition, studies on the production of this alloy as porous material and its application in living environment are continuing [13-15]. This is why niobium is added to obtain a low elastic modulus $\beta$-phase alloy, thus preventing the wear of the bone. In addition, the porous structure enables the formation of more intimate bonds between the implant and bone tissue, the transport of nutrients within the body, and the progression of substances such as blood and bone tissue [16-19]. For this reason, in this study, it was tried to produce porous and Ti-based Ti-10Nb alloy implant material by conventional sintering using high purity titanium and niobium element powders.

\section{Method}

In this work, high-purity $\mathrm{Ti}$ and $\mathrm{Nb}$ powders were mixed at $\mathrm{Ti}-10 \mathrm{Nb}$ atomic ratios. The $\mathrm{Ti}-10 \mathrm{Nb}$ atomic ratio was favored mainly to obtain the $\beta$-phase structure according to the binary Ti-Nb equilibrium diagram. The mixed powders were briquetted in a specially manufactured mold at a pressure of $300 \mathrm{MPa}$ in the form of a cylinder of 10x15 mm and then sintered in an argon gas protected oven at $1400{ }^{\circ} \mathrm{C}$ for 2 hours. Also, for comparison, pure Ti powders were similarly sintered by briquetting with the same pressure. The distributions of the phases in the microstructures of the samples were examined by SEM and XRD. The compressive strength and elastic modulus of the samples were determined by compression test.

\section{Results and Discussion}

The pore ratios of the Samples produced in this study are low for an ideal implant. For this reason, the use of poreforming extra materials such as ammonium bicarbonate in the production of samples will benefit future work. Such alloys have been started to be studied in the literature yet and they continue intensively. SEM and XRD analyzes confirmed the presence of single-phase structures for pure $\mathrm{Ti}$ and $\alpha$ and $\beta$ phases for Ti-10 $\mathrm{Nb}$ as well as $(\alpha+\beta)$ Widmanstätten-like structures. In addition, the presence of $\alpha$ "martensite buildup was detected with XRD patterns. It was determined that the elastic modulus of the produced samples was very close to that of hard bone tissue. The $\beta$-phase structure is formed by the addition of $\mathrm{Nb}$ to the elastic modulus of the samples. The Ti-10Nb specimen produced is a more ideal implant material than the pure Ti sample in terms of microstructure and mechanical properties. 